\title{
GUADALUPE Y JUAN DIEGO: ACTITUDES Y TESIS CONTRAPUESTAS SOBRE SU HISTORICIDAD'
}

\author{
Dt. P. Fidel González Fernández mcej
}

En la historia de la controversia guadalupana se encuentran tesis contrapuestas. Algunas quieren vaciar Guadalupe de su historicidad y reducirlo a un mero símbolo de valor variable. Sintetizamos algunas de estas tesis que se repiten en las controversias desde principios del siglo XIX.

a.) Algunos reducen "Guadalupe" a un puro mito que representaria las antiguas tradiciones religiosas mexicanas sincretisticamente asumidas por el catolicismo. En este sentido la Virgen de Guadalupe seria una transposición católica de una "divinidad" pagana y Juan Diego uno de los personajes del mito.

b.) Otros antiaparicionistas juzgan Guadalupe como un instrumento catequético usado por los misioneros en la evangelización de los indígenas; habrían aplicado asi al caso mexicano una fuerte tradición española que usaba el teatro, las escenificaciones, los pasos de las procesiones (son famosos los de Semana Santa, las representaciones de la Navidad, etc.); todo ello ha dado lugar a una rica tradición escultórica e iconográfica de la que la Virgen de Guadalupe sería parte.

c.) Otros ven en Guadalupe una creación del Criollismo a partir del siglo XVII como bủsqueda de una afirmación de poder frente a los peninsulares españoles; tal contraposición se verificaba en todos los ámbitos de la vida social, política y eclesiástica a partir del finales del siglo XVI. Habria nacido así el nacionalismo mexicano con raíces criollas y la Virgen de Guadalupe como su símbolo. Solamente en un segundo tiempo se daría espacio al "indio Juan Diego" y con él a los indígenas (indios), que no habrian sido recordados como protagonistas en el hecho hasta entrado el siglo XVIII. La misma Independencia mexicana-según autores como S. Poole ${ }^{2}$ - babria sido proclamada en este sentido y bajo este simbolo.

'El presente aruculo es conanuación ded publicado en el anterior nümeno de nuestra revista con el tirulo "La historicidad del encuentro de la Virgen de Guadalupe y Juan Diego" Revista STUDIUM, n* 1, 2000, pp.35-58. Sendos artículos estàn relacionados con las ideas expuesias por el autor en el carso dirigido en nuestra Unversidad en agosto del 2000.

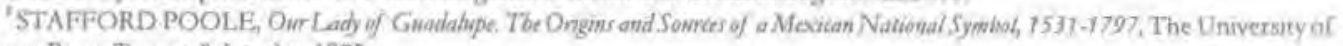
Arzona Press, Tueson \& Landon 1995. 
d.) Para otros antiaparicionistas la duda nace de la falta de fuentes precisas o poco seguras contemporáneas al hecho; pesa mucho sobre ellos el llamado "silencio documental franciscano", especialmente el de fray Juan de Zumárraga y el de otros cronistas de la época, sumamente fieles en la transmisión de los hechos más importantes de la conquista y de la evangelización. Estos objetores sobre la historicidad guadalupana entre los que se encuentra Joaquin Izcalbalceta no se cerrarian al hecho en si mismo; subrayarian sobre todo la falta de documentos históricos exhaustivos.

e.) Se dan también una serie de escritores sobre el hecho guadalupano que no niegan su historicidad en sí misma. Para ellos la historia en sí no es importante, lo fundamental seria el simbolismo guadalupano. Tal parece ser la posición que se desprende, por ejemplo, en la obra de Richard Nebel.

f.) Para algunos sostenedores de la llamada teología de la liberación o también de una nueva teologia indigenista lo interesante en el hecho guadalupano es el papel de los indigenas y el drama de la conquista y de los primeros momentos de la evangelización. El hecho guadalupano y el papel de Juan Diego es interpretado a partir de aquella "teologia". Por motivos opuestos algunos escritores e historiadores hijos del idealismo filosófico leen con tal prisma filosófico el hecho guadalupano interpretándolo dialécticamente y como una creación del sujeto.

g.) Se encuentran tambićn numerosos escritores y divulgadores de la devoción guadalupana y juandieguina que escriben sobre el argumento preocupados por motivaciones de religiosidad popular o devoción mariana sin alguna preocupación de carácter histórico. Frecuentemente, en sus argumentaciones se dan cita muchas de las posiciones señaladas. Frecuentemente en estos escritos prevalece el sentimiento réligioso sobre el rigor histórico y se da por buena una literatura frecuentemente superficial.

h.) Estas visones aplicadas al hecho guadalupano caen consciente o inconscientemente en un fideísmo; algunos soslayan el problema de la racionalidad de la fe y de su nexo con la historia y otros la reducen a puro simbolo sin ninguna relación con los hechos históricos. Veamos algunas de estas posiciones de la historia del antiaparicinismo guadalupano y sus motivaciones de fondo.

\section{PROBLEMÁTICA SOBRE LA HISTORICIDAD DE JUAN DIEGO.}

\section{La Causa de beatificación de Juan Diego}

Juan Diego Cuauhtlatoatzin nació al parecer hacia el 1474 y debiô morir en 1548 ,

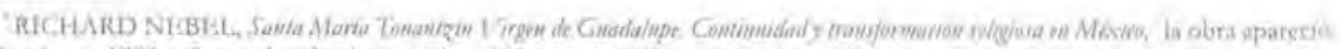

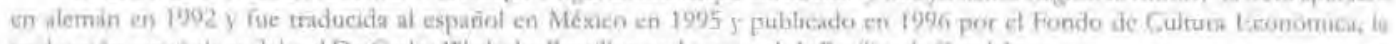

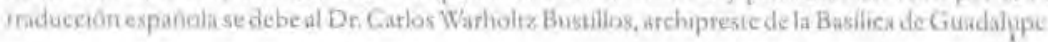


es el vidente de Santa María de Guadalupe y su "embajador-mensajero" como es llamado por algunas de las primitivas fuentes indigenas guadalupanas. Fue beatificado precisamente en basílica de Guadalupe de la ciudad de México el 6 de mayo de 1990 por SS. Juan Pablo II durante su $2^{\circ}$ viaje apostólico a México.

La historia de su Causa está estrechamente unida al de del hecho guadalupano desde un punto de vista jurídico se abrió un proceso en 1666 para reconocer el Hecho. La petición fue firmada por el Obispo de Puebla, Gobernador de la Arquidiócesis de México, sede vacante, y por el virrey de la Nueva España. En 1667 la Santa Sede recibió la misma petición que fue solamente fue leída ${ }^{5}$.

En el siglo XVIII, en 1739 el erudito e historiador Lorenzo Boturini Benalluci recogió una buena cantidad de documentos sobre el hecho Guadalupano y sobre el indio vidente Juan Diego; muchos de estos documentos se perdieron cuando el erudito citado fue expulsado de la Nueva España; sin embargo, más adelante algunos serían hallados en archivos y colecciones privadas ${ }^{6}$.

Benedicto XIV acogió las peticiones de las autoridades eclesiásticas y civiles dela Nueva España y declaró la Virgen de Guadalupe en 1754 como patrona principal de la Nueva España. Por su parte ya entonces ya la sagrada congregación de los ritos concedió misa y oficio especiales para el 12 de diciembre, solemnidad de Nuestra Señora de Guadalupe. Finalmente en el siglo XIX, a pesar de las agitaciones, contrastes y guerras civiles e incluso persecuciones religiosas en México, los obispos mexicanos obtuvieron en 1894 la concesión por parte de la sagrada congregación de ritos la coronación canónica de la Virgen de Guadalupe ${ }^{8}$, en la petición para la coronación fueron presentadas de nuevo las Informaciones Jurídicas de 1666 usadas como respuestas a las "animadversiones" (dificultades suscitadas sobre el caso). En el México de las primeras décadas del siglo XX, sumergido en continuos dramas y guerras civiles la Virgen de Guadalupe y su "mensajero" Juan Diego constituyeron un punto constante de referencia para el pueblo católico; la devoción guadalupana fue el sostén de este pueblo en los momentos más violentos de la persecución: muchos mártires (algunos ya beatificados) murieron gritando "Viva Cristo Rey Viva la Virgen de Guadalupe".

En 1974, al celebrarse el V Centenario del hipotético nacimiento de Juan Diego algunos en México propusieron ya su canonización con el objetivo de proponerlo como

\footnotetext{
'Cfu CONGREGATIO PRO CAUSIS SANCTORUM, 184, Mextana Camonizationis Serwi Dej Ionnu Didaci Cuatiblatoul in 1 in

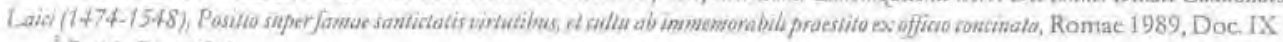

Positio, Doc. X,1.

Pasitio, Doc, XI, 5.

Positio, Doc, XI, 9

'Pasitio, Doc XII, 8 .
} 
modelo de seglar cristiano". SS. Juan Pablo II habló de Juan Diego como de un personaje histórico y fundamental en la historia de la evangelización de México durante su 1 ra. Visita pastoral a México en 1979, y los obispos mexicanos volvieron a insistir sobre su canonización hecho profundamente sentido por gran parte del pueblo mexicano. Se dieron entonces los primeros pasos y el 15 de junio de 1981 la conferencia episcopal mexicana pidió formalmente su canonización durantes $\mathrm{X}$ Asamblea.

La Congregación para la Causa de los Santos informó al entonces arzobispo de México el Cardenal Ernesto Corripio Ahumada de los pasos necesarios en tal sentido el 8 de junio de $1982^{10}$. Fue nombrada entonces una comisión histórica que preparó el material necesario en tales casos. El 19 de enero de 1984 se nombró un postulador en Roma y se llevó adelante el proceso canónico ordinario exigido en tales casos desde el 7 de enero de 1984 hasta el 23 de marzo de 1986. La Congregación Romana para la Causa de los Santos aprobó el camino andado el 7 de abril de $1986^{11}$.

\section{Oposiciones y Problemas}

Algunos eclesiásticos y seglares mexicanos se opusieron a la bearificación de Juan Diego negando su historicidad. Para estos eclesiásticos Guadalupe y Juan Diego pertenecerían al ámbito de la carequesis simbólica; ir más allả de tal simbolismo sería una mera quimera histórica; además una "canonización" de Juan Diego seria la canonización de un simbolo y no la de una persona; por ello tal hecho comprometería gravemente el Magisterio del Papa. Estos eclesiásticos y otros que comparten la misma opinión no ven alguna contradicción de esta posición con la devoción guadalupana, en cuanto devoción mariana importante en la historia de México.

En 1995 apareció la obra del sacerdote historiador norteamericano Stafford Poole, Our Lady of Guadalupe. The Origins and Sources of a Mexican National Symbol, 1531 $1797^{12}$. En tal obra el autor afirmaba, como ya el título indica, el origen simbólico, religioso y nacional, de Guadalupe como instrumento del criollismo, a partir de mediados

\footnotetext{
'Cfr Posilio, Doc XIII, 119 . 3/1982.

"Carta S. Congregación para la Causa de los Santoral cardenal Frnesto Cormpio Ahumada el 8 de junio de 1982, prot. N. 1 a08.

"E primer pestulador de la Gausa fue d P Antonio Cairoli OFM. que seria sustimudo despuès de sta muerte por el P Paofo

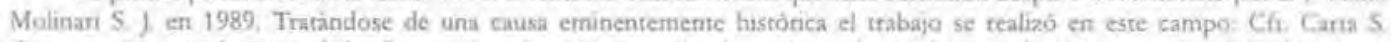
Congregación para la Causa de los Santos al ardenal Ernesto Corripio Ahumada el 8 do junio de 1082, prot N 1408-5/1982. pp. XVI-XXIV: XIX_ Fsea Pesilie tiene sin duda el mérito de haber ofrecido documentos importanres para sostener la histoncidad de lor hecho y a puesto de manifiesta algunos aspectos importantes, sin embargo, desde un punte de vista metodológica de la histora of́recia numerosas dudas o puntos débiles coma relevaron algunos Consultores Historiadores (efr. Relatio et Vota de los consuitores historiadores del 30 de enero de 1990 y de los consultores teólogos del 30 de marzo de 1990.

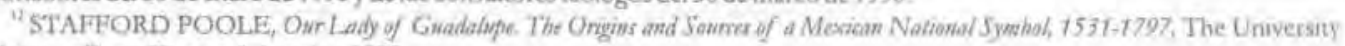
of Arizona Press, Tucson \& Londan 1995.
} 
del siglo XVII para imponer su propia afirmación de poder de frente a los peninsulares españoles y dar un fundamento religioso en el contexto católico del tiempo a una mexicanidad que con el tiempo desembocatía en la Independencia. Por lo tanto para Poole ni las apariciones ni Juan Diego tendrían una base histótica; serian simples símbolos fabricados que con el pasar del tiempo se impondrian en la devoción y opinión pública mexicana como un hecho histórico.

Otros autores recientemente han interpretado Guadalupe como un mitosímbolo que ha ayudado en la construcción de la identidad mexicana, o al menos como expresión máxima del hecho cristiano en la antigua mentalidad y cultura tradicional de los mexicanos, y por ello como el símbolo del encuentro con el nuevo mundo religioso llevado por los españoles. Una de estas obras más significativas es la del alemán Richard Nebel ${ }^{15}$.

Dado que muchos obispos y la mayor parte del pueblo mexicano pedian la canonización del beato Juan Diego, a principios de 1998 la Congregación para la Causa de los Santos quiso andar a fondo sobre la problemática histórica por lo que nombró una comisión histórica encargada de examinar la documentación histórica existente y ahondar en el estudio de algunos problemas pendientes.

El volumen de Fidel González Fernández Eduardo Chávez Sánchez José Luis Guerrero Rosado, El encuentro de la Virgen de Guadalupe y Juan Diego, editado por Pornúa, México 1999, y actualmente (2000) en su cuarta edición, es fruto de tales trabajos y presenta sumariamente algunos de los resultados de tal investigación recogida en 24 secciones temáticas de problemas y documentos de archivo.

Las dudas y objeciones suscitadas por diversas obras publicadas recientemente merecen una atención seria del historiadór; ellas constituyen un estímulo positivo para la investigación histórica sobte el Acontecimiento Guadalupano de manera más completa y profunda sin censurar ninguna objeción razonable. El trabajo que aquí presentamos no tiene como objeto una apología acrítica de la historicidad del Acontecimiento guadalupano y del indio vidente Juan Diego. Nuestro objetivo es presentar una serie de documentos de procedencia diversa que a nuestro entender afirman de manera convergente y no prefabricada el hecho guadalupano. Por lo tanto ha sido nuestra preocupación evitar prejuicios o tesis preconcebidas a la hora de examinar la documentación a nuestra disposición. Ello no quita que se presenten algunas hipótesis razonables de carácter histốrico para explicar en algunos casos posibles dudas o vacíos

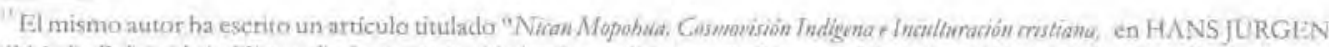

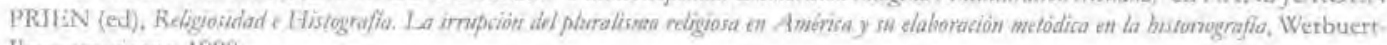
Tberoamericana, 1998 . 


\section{Dr. Fidel González Fernández meç}

(como el llamado "silencio guadalupano" de algunos personajes eclesiảsticos y civiles del siglo XVI).

\section{METODOLOGLAAPLICADA}

Quienes hemos elaborado el trabajo aquí presentado hemos querido seguir una camino rigurosamente crítico histórico en la búsqueda documental y en la valoración crítica de los documentos. Para ello hemos comenżado una investigación de carâcter archivistico y bibliográfico en aquellos archivos y bibliotecas donde razonablemente se esperaba encontrar alguna documentación relativa al caso. No se nos podía tampoco escapar el hecho de una hipotética canonización de Juan Diego, a diferencia de muchas otras, tendría una resonancia mundial.

Tratándose de una Causa eminentemente hístórica con características muy peculiares, dado el tiempo, el ambiente, y la naturaleza de la documentación nos hemos dado cuenta que se tenian que estudiar los distintos problemas hístóricos respetando sus características peculiares y la indole histórica de tal documentación. ¿Cuáles han sido los criterios de la investígación? Para alcanzar nuestro propósito hemos intentado seguir dos criterios fundamentales del método usado en la Congregación vaticana para las Causas de los Santos: a) investigar "plene ac rite", es decir, con los criterios de la metodología crítico-histórica . b. Tratando de averiguar si las fuentes son dignas de fe, total o parcial, y en que medida; c. Ver si en tales fuentes se pueden encontrar aquellos elementos que puedan oftecer un fundamento histórico sólido para llegar a un juicio sobre la historicidad del acontecimiento guadalupano de México y de su nexo con el personaje vidente Juan Diego.

En este orden de cosas hay que tener presente la naturaleza y la diversa tipologia de las fuentes históricas y literarias a nuestra disposición, y por lo tanto, la metodología adecuada que debe aplicarse a cada caso.

Las fuentes históricas y literarias en nuestro caso son de naturaleza muy diversa. Proceden fundamentalmente de tres matrices culturales distintas: las "estrictamente indias e indigenas"; las "españolas"; $y$ las "mestizas" donde se dan cita los dos elementos anteriores en manera diversa. Bl tratamiento de cada fuente lo impone la fuente misma y su naturaleza y no la posición del sujeto que examina la fuente.

En el estudio y en el uso de las fuentes el historiador trata de aplicar tres criterios o condiciones fundamentales a la actitud con las que las estudia: 


\section{GUADALUPE Y JUAN DIEGO: ACTITUDES Y TESIS CONTRAPUESTAS SOBRE SU HISTORICIDAD}

a.) Ante todo el "realismo", es decir, el prevalecer del objeto sobre el ánimo del sujetoy sobre su ideología a priori o el prejuicio: el método de investigación lo impone el objeto y no es determinado o imaginado ideológicamente por el sujeto.

b.) La "racionalidad"; si el sujeto que obra es el hombre, hay que ver como la racionalidad coincide con la actuación dl valor de la razón en el obrar; es decir, la capacidad darse cuenta de lo que realmente ha acontecido, "del hecho histórico", según la totalidad de sus factores sin eliminar o descuidar alguno. En la investigación histórica se llega a conocer el objeto, el hecho histórico acontecido, a través de un procedimiento o proceso criticamente razonable. Para conocer ciertos hechos de la historia se debe seguir un método apropiado que tenga presente la naturaleza de tales hechos y de las fuentes que nos los atestiguan; esta exigencia nace de la razón que estudia el objeto siguiendo pasos y motivos adecuados, desarrollando caminos diversos según el objeto estudiado (el método lo impone el abjeto). Si no se tiene en cuenta esto, fácilmente se cae en errores de valoración o de reducción. La seguridad o el conacimiento cierto de algunos valores no se quede alcanzar siguiendo solamente o exclusivamente métodos "matemáticos", "galileianos" o "positivistas", que excluyan factores no comprobables según la exigencia matemática; por ello en la investigación histórica para alcanzar una seguridad hay tener también en cuenta la certeza moral, la certeza existencial, la certeza que proviene de la tracción continua y segura, y con una propia aplicación según el método crítico a nuestro caso.

c) El influjo de la moralidad en la dinámica del conocimiento de los hechos de la historia constituyen, por lo tanto, una tercera premisa que frecuentemente se debe aplicar al conocimiento histórico; esta actitud limina el preconcepto.

Por todo ello, a la hora de estudiar el acontecimiento guadalupano el historiador tiene que tener en cuenta la historia y la cultura mexicana prehispánica, la de los conquistadores y misoneros españoles y el proceso evolutivo histórico que se da en la Nueva España o México desde el siglo XVI en adelante. Para dar un justo valor a las correspondiente fuentes históricas el historiador debe tener presente también los hechos de interculturación de los dos mundos: su lenguaje cultural, el valor de sus tradiciones, el método de su transmisión. El historiador se encuentra por ello delante de problemas de crítica histórica en los que hay que evitar el descuido de la premisas citadas.

\section{Notas sobre las fuentes indigenas}

Las fuentes indigenas guadalupanas ocupan un papel fundamental. Ante todo hay que establecer su ptöcedencia, su cronología, y su finalidad. Entre las fuentes indigenas destaca la fuente "principe", "El Nican Mopohua", atribuido al escritor indio Antonio 


\section{Dr. Fịdel González Fernândez mcçj}

Valeriano, de cuya paternidad hoy día los mejores investigadores ya no dudan. El Documento tiene una estructura poética y se trata "de un testimonio privilegiado del proceso de trasculturación del cristianismo de Nueva España, el cual sigue manteniendo un valor y una actualidad ejemplar para la introducción a filosofias y teologias mexicanas, así como para la praxis teológico y social y para la pastoral eclesiástica en el México actual y en otros países de América" contenido y de cuanto en él es revestimiento literario o parte de un entorno cultural sigue siendo discutido con vehemencia.

El documento de Antonio Valeriano fue dado a conocer en su texto náhuatl por Lasso de la Vega en 1649. "Es un texto complejo y simple a la vez que se convirtió en el paradigma para otros relatos posteriores y que influye decisivamente en el proceso religioso de México. En este texto en náhuatl lo que más destaca, como ya lo había expresado el historiador y nahuatlaco A. Maria Garibay es el extraordinario mensaje de la marernidad espiritual de María, principalmente hacia lo pobres y los desamparado" "ts

Por todo ello, el documento va estudiado en su contexto cultural completo. Un autor atento y al mismo tiempo crítico sobre el acontecimiento guadalupano subraya como este tipo de documentos y en concreto el Nican Mopohsa hay que estudiarlo en lo que él llama "la configuración literaria del Acontecimiento Guadalupano" "toniendo presente las reflexiones filosóficas y recensiones teológica del acontecimiento guadalupano", y la "cosmovisión náhuatl (tolteca-azteca) y cristiana. Cada palabra de los 218 versos del Nican Mopohwa tiene sus significados dentro de la filosofia y mitologia nahuas asi como cristianas respectivamente, ${ }^{\text {,18. }}$.

El misma Nebel reconoce la complejidad y la amplitud de la cosmovisión náhuatl y del profundo intento de inculturación cristiana por obra de los misioneros Para entenderlo hay que tener presente todos los datos que nos ofrecen las fuentes históricas y literarias de los siglos XVI y XVII en la Nueva España.

Ante todo para interpretar los documentos indígenas tenemos que echar mano de toda la literatura y fuentes históricas del México de aquel tiempo. Asi escribe Nebel:

"EI medio instrumental que hay que usar en la interpretación del Nicrut

Mapahtua no es otro que el de las fuentes: las historias y relaciones de Bernardino de

Sahagưn, Andrés de Olmos, Diego Durản, Diego de Valades, Jerônimo de Mendieta,

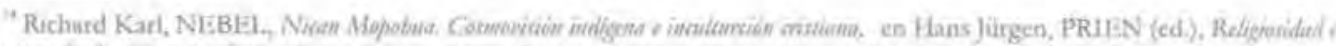

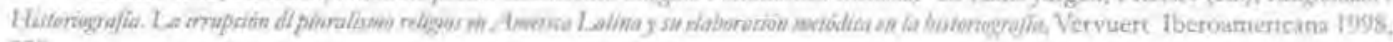
238.

"Richar Kart, NBBELL, Llidew, 236.

"Richar Karl, NBBE:L, Itiden, 238 :

"Ruchar Karl, NEBEL, Lbinkm, 230

"Richar Kart, NEBlil I Tarlew, 240
} 


\begin{abstract}
Juan de Torquemada, etc, aluden a la existencia de sabios filósofos nahuas. Entonces es necesario a acudir a fuentes más directas, al testimonio inmediato expresado por lo indios en su propia lengua. Pata ello se utilizan, por ejemplo, las siguientes restimonios en náhuat de los informantes de Sahagún; el Libro de los Coloquios de los Doce; la Colección de "Cantares Mexicanos", Huehuehtlatolli, o plática de los viejos; Códice Chimalpopoca, y otros escritos fundamentales.

Los sabios tlamatinime expresan sus pensamientos a travès de la metáfora. Conocer la verdad fue para ellos expresar con "flores y cantos" el sentido oculto de las cosas tal como su proprio corazón "endiosado" les permitía intuirlo. Entre los tlamatinime podemos recordar a NezahualcóyotI, Nezahualpilli, Cuacuauhtzin (Texcoco), Ayocuan Cuetzpaltzin, Xayacamach, Tochihuitzin, Tecayehuatzin (región poblano tlaxtcalteca) y a Tlacaélel (México-Tenochtitán). Todos los cuicapicque, "forjadores de cantos": sacerdotes, príncipes, gobernantes, pintores, músicos, escultores, arquitectos y astrólogos, buscaban en el fondo lo mismo, su propia verdad, la del universo, el origen del hombre y el tema de la muerte.

Este pensamiento náhuatl, que conocemos principalmente a través de los rextos que nos hablan de su florecimiento en los siglos XV y XVI, es consecuencia de una larga evolución cultural, es heredero de lo que mucho antes elaboraron los toltecas, los teotihuacanos y aún los más antiguos inventores del calendario, los creadores de lo que se ha designado por "cultura madre". Al tomar conciencia parecen resumirse y recrearse por lo menos tres milenios de actividad intelectual, se vuelve más fácil explicar y concebir su extraordinaria riqueza que se refleja también en el Nican Mopobua,"19
\end{abstract}

En la interpretación de las fuentes indígenas guadalupanas hay que tener en cuenta también que estas no son "puras" en el sentido cultura y lingüístico sino que proceden ya de indígenas cristianos o que han entrado en contacto con el mundo cultural español y misionero. Estos contactos se reflejan en las fuentes, sea en el contenido como en el lenguaje. Por ello, para entender estas fuentes se debe tener presente el riquísimo mundo literario náhuatl de temas religiosos, filosóficos y de ciencias naturales producido por indígenas y por españoles después de 1521. No hay que olvidar la procedencia humanista de muchos frailes misioneros y conquistadores. Tal humanismo cristiano se encontró con la sabiduria tradicional india. Antonio Valeriano es un ejemplo, frailes misioneros. Conquistadores y sabios indigenas nos han legado numerosas investigaciones lingüísticas y filológicas: "artes o gramáticas, vocabularios, doctrinas cristians, catecismos, sermonarios, devocionarios, confesionarios, traducciones dela biblia, anales y relatos orales, compilaciones de cartas, poemas e himnos sagrados, textos sobre agricultura, medicina, conjuros y hechizos, fiestas y bailes, educación y sociedad y economia y otras obras a través de los sigłos de la Colonia y de la Independencia hasta los

\footnotetext{
${ }^{16}$ Richar Karl, NEBEL, Ibidem, 243-244.
} 


\section{Dr. Fidel González Fernández mecj}

tiempos actuales en los que nuevo textos en náhuatl incluyen vocablos e ideas especialmente diseñadas para significar conceptos hebraico-cristiano. Esta rica literatura, largo tiempo desdenada por los investigadores, es pródiga en implicaciones en el contexto de la historia de las ideas y de procesos de aculturación en el ámbito de las creencias y prácticas religiosas así como en ideas modernas y filosóficas" ${ }^{200}$.

Estos principios y experiencias deben tenerse presentes no solamente en el caso especifico del Nican Mopobua, sino también en la ríca literatura escrita en lengua náhuatl acerca del acontecimiento guadalupano. Tal literatura ha venido ejerciendo un influjo notable tanto en creaciones modernas teológicas como literarias como las de Juan Rulfo, Octavio Paz yotros ${ }^{2 !}$.

Finalmente hay que notar que la lengua náhuatl es rica en expresiones literarias para expresar poéticamente hechos de la cosmovisión mesoamericana y de su historia. Esta lengua además era la lengua "franca" de mesoamérica usada por numerosos poetas, cronista y literatos en tiempos antiguos y en los tiempos inmediatamente posteriores al acontecimiento guadalupano. Los hechos y el mensaje de la doctrina cristiana fueron también expresados en ella con la misma metodología, los mismos acentos y el mismo desarrollo del pensamiento filosófico de los antiguos "tlamatinime", los sabios mexicanos forjadores de cantos, crónicas y poesía. Este aspectó de la inculturación náhuatl cristiana explica el estilo y el contenido de estos documentos indigenas.

\section{En relación a las fuentes españolas y europeas en general}

Los documentos del siglo XVI de "procedencia española" a favor de Guadalupe son numerosos pro también aquí nos encontramos con la misma problemática y de lectura de los documentos de procedencia india o mestiza escritos en náhuatl o en español.

La mayor parte de los documentos presentados en apoyo del acontecimiento guadalupano pertenecen a la segunda parte del siglo XVI y crecen cada vez más hasta nuestros días. Frecuentemente estos documentos se refieren directamente $a$ indirectamente al culto dado a la Virgen de Guadalupe en la capilla homónima a ella dedicada en la Villa de Guadalupe, a las afueras de la Ciudad de México. Tales fuentes no siempre se refieren al hecho directo de las apariciones a veces se trata de documentos circunstanciales en los que se recuerda "Guadalupe" de paso; otras veces estos documentos otras veces tienen como objeto donaciones o actos de devoción guadalupana, otras veces se refieren a cuestiones jurídica relativas al santuario de Guadalupe o a controversias... No siempre en ellas aparece con claridad una referencia a

\footnotetext{
"Richar Karl, N12Bt:L, Ihiden; 244

"TCF, Richar Karl, NIEBEL, 10item, 245.
} 
las apariciones o al vidente Juan Diego. Tambiẻn aquí hay que estudiar el origen, el destinatario, el contexto y la finalidad del documento para entender su propósito y alcance. De hecho algunos de estos documentos no tienen como finalidad el tema guadalupano directo sino más bien otras cuestiones; pero el hecho de una afirmaciôn "guadalupana" les da un mayor valor.

Actualmente uno de los puntos más discutidos en relación a las fuentes guadalupanas españolas es la existencia de documentos anteriores a 1548, es decir, de las dos primeras décadas inmediatamente sucesivas a 1531 fecha que la tradición y el resto de los documentos dan al acontecimiento guadalupano. No poseemos actualmente algún documento sobre el asunto del primer obispo de México, el franciscano fray Juan Zumárraga (+ 1548). Los antiaparicionistas esgrimen este "silencio" documental como el argumento más fuerte contra el acontecimiento guadalupano; mientras que los aparicionistas o sostenedores del acontecimiento guadalupano ofrecen varias hipótesis para explicar tal "silencio". De todas maneras habria que aplicar aqui el principio jurídico de que el "silencio" no afirma ni niega nada; sin embargo, no se puede tampoco afirmar la posibilidad de la existencia de documentos de Zumárraga perdidos en archivos o bibliotecas, la cuestión queda por lo tanto abierta.

Las fuentes "españolas o europeas" crecen a partir del segundo arzobispo de México, el dominico Alonso de Montúfar. El guadalupanismo de los arzobispos mexicanos es creciente e indiscutible. A lo largo del siglo XVII "Guadalupe" se une cada vez mâs con la conciencia católica mexicana y con el sentido indiscutible de la "mexicanidad" y pertenencia nacional esta experiencia relígiosa católica constituye la base más fuerte de la identidad católica nacional mexicana. En este juicio coinciden los mayores autores guadalupanos sea aparicionistas como antiaparicionistas (como últimamente Stford Poole) o autores que sin objetar la historicidad en sí se inclinan por dar a Guadalupe un valor teligioso y cultural simbólico como en el caso de Richard Nebel que escribe: "En términos socioculturales, la veneración de la Virgen de Guadalupe permite a los indígenas, gracias a las circunstancias particulares de su aparición a un pobre indio la reivindicación de sus reclamos de respeto y de reconocimiento dentro de la sociedad colonial y de su participación de la esperanza de la salvación. [...] La Virgen de Guadalupe no fue propiedad de los conquistadores ni de los indios se torno en elemento decisivo en el largo proceso de formación de una cultura mexicana mestiza, con un marcado distanciamiento del mundo hispano de donde provino. Su doble origen hispano-indio reflejaba la disposición sociocultutal de los mestzzos, incluso los criollos en la Nueva España. La que antes era la bandera de los conquistadores españoles se volcó contra ellos en la guerras de independencias. "Viva la Virgen de Guadalupe y mueran los gachupines!" era uno de los gritos de batalla de la 


\section{Dr. Fidel Gonzălez Fernândez mccj}

hueste rebelde. Asi, la Virgen se transforma en un símbolo d la continuidad de la vida y de las culturas en México. Representa un punto culminante de las fuerzas religiosas y creadoras de la nación mexicana. Por eso no es sorprendente que haya sido punto de partida de movimientos sociales, culturales, religiosos y políticos, que ya desde el siglo XVII favorecieron en buen grado, tanto su evolución hacia la independencia de España, la madre patria, como el surgimiento de una conciencia nacional 'mexicana",22,

Nuestra investigación histórica tiene como objetivo la presentación de las fuentes históricas que en su diversa procedencia y naturaleza muestran una convergencia hacia la afirmación de la historicidad.

\section{El trabajo de investigación histórica} direcciones:

Nuestro trabajo de investigación ha querido investigar en las siguientes

a. Investigaciones en México sobre las fuentes indígenas y españolas:

- Estudio histórico crítico de los documentos indígenas.

- Investigación en el archivo de Guadalupe, en el Archivo General de la Nación, en el archivo de la Curia Metropolitana, en el archivo del Cabildo, entre otros.

b. También se hicieron investigaciones en archivos de Viena, sin éxito positivo al respecto.

c. Investigaciones en archivos de España: en los principales archivos españoles con material documental relativo a la historfa civil y religiosa de México desde el siglo XVI al XVIUI.

d. Las investigaciones en estos archivos fueron arduas: dada la cantidad y complejidad de documentos y de fuentes y al estado en el cual se encuentran estos archivos, sobre todo en México (como el de la Curia, etc.). El campo de investigación de archivo se presenta todavía bastante amplio; la experiencia de este trabajo nos demuestra la existencia de numerosos documentos che directa o indirectamente tienen noticias que tocan el hecho guadalupano y a Juan Diego. Por lo cual la investigación debería todavía ir adelante. La documentación encontrada confirma las conclusiones convergentes de nuestras investigaciones. e. Se ha tratado de conseguir documentación que abarcase el primer período franciscano en México. Sobre todo en la posible documentación procedente de Zumárraga y dirigida, hipotéticamente, en tres direcciones: a) a la Corona; b) a la Santa Sede (Archivo Vaticano); c) a los Superiores Franciscanos en España, especialmente con aquellos a él ligados por vínculos jurídicos o por

\footnotetext{
${ }^{2}$ Richar Karl, NEBFil, lbides, 237-238.
} 
amistad en los conventos franciscanos españoles. Hasta el momento, tales investigaciones no han tenido el éxito esperado. No obstante, al estado actual de las investigaciones el asi llamado "silencio" de Zumárraga no representa un obstáculo dirimente o impediente contra la historicidad: dada la existencia de otra abundante documentación, pero es necesario explicar este "silencio". Es cuanto trataremos de hacer expresamente.

f. La misma observación es valida para las investigaciones sobre la documentación de origen franciscana: se ha indagado en diversos archivos franciscanos relacionados con la historia misionera en América española (como el de los franciscanos en Madrid). El éxito negativo se explica en el mismo sentido señaladó para Zumárraga; pero en algunos testimonios de los primeros franciscanos se puede verificar una hostilidad hacia el hecho guadalupano, por miedo de un hipotético sincretismo de parte de los indios.

g. El Archivo Secreto Vaticano y la Biblioteca Apostólica Vaticana: han constituyen otro campo de investigación de posibles documentos concernientes a la historia eclesial mexicana y por ello a algunos relativos a Guadalupe. Se han encontrado sobre todo documentos pontificios concediendo indulgencias y privilegios a la iglesia de Guadalupe a partir de Gregorio XIII en el siglo XVI.

\section{h. Conclusión:}

1. Hemos realizado un trabajo de investigación en los varios archivos y bibliotecas donde hipotéticamente se podía imaginar la existencia de material documental sobre el hecho guadalupano. El éxito ha sido muy diverso según los lugares y está indicado a lo largo del trabajo. Pero el material localizado, o ya conocido, nos parece que es suficiente para Llevarnos, sin dudas razonables y con una certeza histórica seguin los criterios del realismo, de la imparcialidad y de la moralidad sobre la dinámica del conocer, a la afirmación del hecho guadalupano y de la existencia histórica del protagonista el indio Juan Diego. Ello no esconde las dificultades que esta investigación histórica presenta y la necesidad de continuar críticamente la investigación histórica sobre los temas aún abiertos al debate.

2. Hemos visto como en las diversas fuentes analizadas tenemos una convergencia sobre lo esencial: que en los inicios de la presencia española en México, y precisamente en el valle del Anahuac, después una conquista dura y dramática, en un lugar significativo para el mundo indígena, en el cerro del Tepeyac, surge en breve una iglesia dedicada a la Virgen Maria bajo el nombre de Guadalupe, que no es la misma advocación de la de Extremadura 
en España, y que con una fuerza increíble se convierte en punto de atracción devocional, en señal de una nueva historia religiosa y de encuentro entre dos mundos hasta ese momento en violenta y dramática contraposición.

3. En este lugar en torno a este templo, como una pequeña semilla, se desarrolla una devotio incontenible ya sea de parte de los indios como de los españoles, criollos y mestizos, que ninguno tampoco los influyentes y autorizados frailes misioneros mendicantes - pudieron frenar.

4. Se convierte en el punto de convergencia de los diferentes grupos, "la casa común de todos" que reconocen en Maria, la madre del Señor, la Madre de todos.

5. Esto viene progresivamente señalado por las fuentes: con más fuerza por las fuentes indígenas che marcan los inicios el hecho en si y progresivamente por las fuentes españolas (especialmente en el siglo XVH). Estas fuentes diversas, y en el modo progresivo indicado, se refieren al hecho de que la devotio sea originada por intervención sobrenatural: la aparición de la Virgen a un indio, Juan Diego.

6. Las fuentes indígenas escritas y orales hablan muy pronto de las apariciones e indican con claridad al indio Juan Diego; las españolas son más lentas para nombrar y relevar al mismo, subrayan de más el centro del Evento que es la mediación de la Virgen María.

7. Por lo cual el estudio de las fuentes indígenas en su convergencia esencial y según la naturaleza de cada una, nos lleva a la conclusión de la historicidad del Acontecimiento y del vidente Juan Diego visto siempre por las fuentes como un cristiano virtuoso, mensajero de Maria en aquel dramático momento.

8. Además es necesario tener presente la importancia de la tradición oral como fuente histórica entre los pueblos de cultura principalmente oral, como lo eran los pueblos mexicanos.

9. Otro punto fundamental es el hecho de que en la transmisión de datos históricos, donde también la tradición oral es fundamental, entregado el hecho mismo un siglo de diferencia "no es nada" (de hecho son tres generaciones en promedio), En el hecho guadalupano las fuentes escritas son ya precisas y consistentes mucho antes.

10. Las fuentes históricas que examinamos: tradición oral continua, escritos de naturaleza varia, representaciones (pinturas, esculturas...) y arqueologicas muestran como en torno al Hecho guadalupano se desarrolla una creciente atención y "devotio" a la cual va intimamente ligada aquella de la gran 
veneraciòn popular del vidente Beato Juan Diego Cuauhtlatoatzin. Esta documentación demuestra que habia una tal veneración creciente de Juan Diego ligada al culto de la Virgen de Guadalupe y en cuanto le considera como embajador de la Virgen María.

10.1 Tal veneración es demostrada por là iconografia: vemos a Juan Diego a menudo representado con la aureola de santo en diversas pinturas; en los códices indígenas es presentado con los signos que los indígenas reservan para lo sagrado; entre estas pinturas destaca en este sentido el fresco del convento franciscano de "Ozumba" (Estado de México) de los primeros años del siglo XVII, donde se representa la historia de la primera evangelización de México; en él se puede ver la aparición de la Virgen de Juan Diego en el Tepeyac con todas las características pictóricas que encontramos en los códices. Queda la duda si la parte referente a Guadalupe sea un añadido posterior al resto. Sin embargo ello no le resta valor al testimonio. Hay que subrayar también el hecho de que el mural se halla en el pórtico exterior de uno de los más antiguos conventos franciscanos y que en su iglesia conventual uno de sus altares fue dedicado posteriormente a la Virgen de Guadalupe.

10.2 Las representaciones iconográficas de las apariciones y de Juan Diego siguen cánones precisos que encontramos en los primeros códices indígenas de la segunda mitad del 1500 y en algunas estampas de los inicios del 1600 .

10.3 En los lugares vinculados a la vida de Juan Diego se conserva una viva memoria entre los indigenas, constatable a partir del siglo XVI, con signos crecientes de continua veneración: descubrimiento de una capilla cercana a su casa; el hecho muy común entre los indios del lugar de bautizarse con aquel nombre compuesto (no de uso muy común). El hecho que su tumba no haya sido aun encontrada no despierta asombro, en cuanto que frecuentemente muchas tumbas, también de principales personajes indigenas (como príncipes) y españoles (como aquellas de los más grandes conquistadores, obispos y misioneros) permanecen anónimas. Además parece, que según algunos que sus restos mortales fueron quizás desaparecidos para evitar un presumible culto $^{23}$.

\footnotetext{
"VICENTE DE PAULA ANDRADE, Estudio Histórion subre la Lovenda Guadalupona, 1908, en Porifio, I, pp. 173-177.
} 
10.4 Actualmente se están realizando excavaciones arqueológicas junto a la antigua "capilla" de indios que se construye ciertamente en los primeros años del 1600 y diferente de la "ermita" o iglesia de la Virgen de Guadalupe, cerca al Santuario de Guadalupe, donde fueron encontradas algunas sepulturas. Parece que esta "capilla" haya sido erigida sobre el lugar donde surgía la casa-dormitorio de Juan Diego y por consiguiente un lugar de veneración para muchos indigenas. Las investigaciones son todavía en proceso. Cuantó la tradición oral había transmitido en misma se está revelando precisa: las excavaciones en curso demuestran la existencia de otra capilla del siglo XVI que la continua tradición ubica en los tiempos de Juan Diego y a șu morada cerca de aquella "ermita" (capilla). Se dice que fue sepultado muy cerca de la misma y actualmente hay en proceso investigaciones arqueológicas sóbre el argumento.

10.5 Aquella tradición habla del hecho que Juan Diego se retiró a la "ermita". El hecho es normal en la tradición cristiana, pero también entre la indígena mexicana. De hecho también muchos príncipes mexicanos, según la religión tradicional estimaban como un gran honor, cuando envejecian y no tenian fuerzas para luchar en las guerras, retirarse para servir en los templos de su religión cumpliendo también los servicios más humildes. Tal tradición religiosa es continuada también después del bautismo de muchos de ellos, considerando el servicio cercano a iglesias y conventos un gran honor y una forma de consagración a Dios y para nada humillante Muchas veces se definian ellos mismos como "pobres", "mazehualtzin" como Juan Diego se llama a sí mismo en los documentos. Uno de estos príncipes, don Fernando Cortés Ixtlixochtlil de Texcoco, seguidor y apoyo de Cortés en la conquista, que según una probable hipótesis sería hermano de Juan Diego, se retira después a Toluca donde no es conocido; más tarde parece se fue como sacristán a un convento de los religiosos mendicantes. Aparece también fundado el hecho que haya estado en el convento de San Vicente Ferrer Chimalhuacán; está probado con datos de archivo (referencia explícita en el inventario de la iglesia conventual del convento dominico de Chimalhuacán) donde viene referida la existencia de un fresco que representaba su bautismo; tal fresco se encontraba en el presbiterio de tal convento; pero hoy ha desaparecido fue reformado y blanqueado probablemente en el siglo 
XIX con la deplorable obra de restauración del mismo. Según los técnicos el fresco se encuentra ahora bajo el yeso blanco.

10.6 Está todavia abierta la cuestión de los orígenes sociales de Juan Diego. Si se trata de un pobre indio en el sentido sociológico inmediato. Vuelve la confusión por la interpretación de la traducción de Becerra Tanco (siglo XVII) del Nican Mopolsua. En él se presenta a Juan Diego como "macehualtzintli icnotlapatzintl?", que Becerra Tanco traduce como "un indio plebeyo y pobre, humilde y cándido" y poco después de él otro autores. Por otra parte, la expresión enuncia un lenguaje cortés y casi "protocolario" en el uso lingüístico de notables indios, como se ve a través de otros documentos indígenas. La expresión se podría por consiguiente traducir: "un indito, un pobre hombre del pueblo" o "un indio, un noble pobrecito ${ }^{24}$.

10.7 Los franciscanos al principio permanecieron y hasta hostiles para ta aceptación del culto de la Virgen de Guadalupe (cfr. Motivos del silencio franciscano y la polémica Bustamente-Montúfar) probablemente también por el miedo que entrasen en eso de las supersticiones (efr. Testimonio de uno de los primeros franciscanos conocidos como los "Doce Apóstoles Franciscanos", Motolinia, sobre los "indios visionarios", y también la postura y praxis de la "tabula rasa" propio de los franciscanos de este tiempo en su método de evangelización (destrucción sistemática de códices, templos tradicionales, desconfianza hacia cada clemento cultural y religioso tradicional indigena, etc.).

10.8 Las "informaciones de 1666" es uno de los documentos más seguros, por su naturaleza, objetivo y destinatario: ahi se habla explícitamente de tal veneración popular por Juan Diego.

10.9 La insistencia en el afirmat, a partir de la segunda mitad del 1600, de parte de muchos testimonios, el deseo de una "exaltación" del beato, la promoción de una "devotio" popular para poder iniciar un verdadero proceso de bcatificación (cfr. Propósito explícito de Boturini en el 1700 , confirmaría tambiến la base de un culto popular del Beato, que en la población india, pero también en la española-criolla es precedente a los conocidos decretos de Urbano VIII sobre el culto a los santos (1634), Tales disposiciones cooperaron asuspender cautelosamente tal

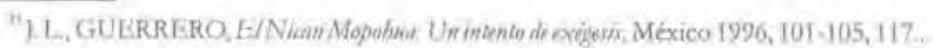




\section{Dr, Fidel Gonzảlez Fernăndez mccj}

culto, pero sin llegar nunca a erradicarlo de la mentalidad popular, como lo demuestran los numerosos documentos de la segunda mitad del siglo XVII en adelante. Tal veneración fue siempre continua y constante, sin interrupción (fama santitatis), y la documentación probatoria, en materia, y muy abundante.

12. Los resultados de nuestra investigación se refieren por consiguiente a los siguientes aspectos:

1. Al hecho de las Apariciones: a) según las fuentes de la tradición; b) según las fuentes escritas.

2. Se examina entonces el problema histórico a través de tales documentos.

3. Se hacen las debidas referencias relativas al culto guadalupano y a Juan Diego.

13. Es necesario tener presente también otros hechos conexos con Guadalupe y Juan Diego

13.1 Constatamos es al inicio de la presencia misionera del Nuevo Mundo, hay una conversión y un gozne entre el mundo antiguo mexicano y el mundo cristiano unido a través de la mediación española. Tal encuentro o gancho entre estos dos mundos fue dramático y humanamente inexplicable como reconocen todos los misioneros en sus relaciones ${ }^{25}$. Ahora bien, Guadalupe fue la respuesta y el indio neo-cristiano Juan Diego Cuauhtlatoatzin su mensajero como es llamado en el más importante documento de indígena sobre el Hecho, el Nican Mopobua. Así lo han percibido tanto la traditio india como aquella española criollaymestiza.

13.2 Esta tradición continua y llega hasta nosotros superando varias peripecias, muchas veces dramáticas, de la historia mexicana, las persecuciones de matriz frecuentemente masónica de los siglos XIX y XX, las presiones externas, etc. Existe una continuidad en la fundamental solidez del Hecho guadalupano y de su participación en él de parte de Juan Diego Cuauhtlatoatzin que trasciende todas las más difíciles conjeturas de la primera evangelización en el Nuevo Mundo y adquiere actualmente un renovado significado eclesial.

\section{En conclusión}

El Hecho guadalupano y su relación con el indio vidente beato Juan Diego Cuauhtlatoatzin tiene un marcado sentido eclesial y misionero de grande significado en

\footnotetext{
${ }^{25}$ Comenzando por el mismo Morolinia que no le veia posible suno a través de un nilagro de la Virgen, como escribrà a Carlos

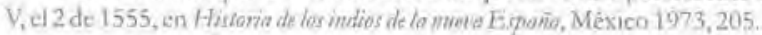


aquel tiempo $y$ hoy actualidad. Escribe S.E. el cardenal Jozef Tomko, prefecto de la Congregación para la Evangelización de los Pueblos: "En el hacerse judio con los judíos y $\sin$ la ley con los que no tienen la ley, el Apóstol (Pablo) muestra no rechazar ninguna condición humana. Nombrando judíos y paganos él entiende referirse a todos los hombres, en cualquier condición en la que se encuentren. [...] Pablo abre la comunidad primitiva al mundo de las gentes, la abre a una experiencia universal. Y apertura significa sobre todo no rechazar a ninguno, entrar en la vida de los demás y comprender". El problema si pone a los inicios de la evangelización del Nuevo Mundo, donde algunos pretendian una asimilación cultural total de esos pueblos y española para llegar hacerlos cristianos. El hecho guadalupano muestrà obviamente la dinámica arriba señalada del anuncio evangélico que asume cada cultura y el sentido religioso de ella y la transforma evangélicamente. El Cardenal cita enseguida un conocido discurso del Santo Padre Juan Pablo 11 en la Universidad Urbaniana del 1980 donde afirmaba: "la fuerza del evangelio debe penetrar en el corazón mismo de las varias culturas y de las diferentes tradiciones". El Cardenal agregaba hablando de la realidad de los hombres como hijos de Dios, "muchas veces huérfanos, no saben reconocer el común origen y viven contradictoriamente mejor en la afirmación de su diversidad que en la búsqueda de aquello que los une. Son autores contemporaneos que teorizan el encuentro de la civilización como matriz de la historia y del futuro. Una civilización encuentra su identidad, crece y se impone porqué se difetencia y se encuentra con las diversas civilizaciones. Como cristianos no podemos aceptar esta perspectiva; debemos actuar parn evitarla. Por esto los pueblos deben sobte todo comprenderse [...] ayudar a comprender las diversas tradiciones en la búsqueda apasionada de la verdad revelada y de las semilla del Verbo presente en el mundo [...] Tenemos en la fe cristiana, la cual no ha sido transmitida por nuestra Iglesia, una energia que no permitirá llegar al fondo. Es la fuerza de la Palabra, del diálogo, del encuentro, de la caridad evangélica"26.

Juan Pablo II en su úlcima enciclica "Fides et Ratio", escribe que: "El proceso de encuentro y confrontación con las culturas es una experiencia que la Iglesia ha vivido desde los comienzos de la predicación del Evangelio. El mandato de Cristo a los discipulos de ir a todas partes "hasta los confines de la tierra" $(H i b, 1,8)$ para transmitir la verdad por Él revelada, permitió a la comunidad cristiana verificar bien pronto la universalidad del anuncio y los obstáculos derivados de la diversidad de las culturas, [...]Ante la riqueza de la salvación realizada por Cristo, caen las barreras que separan las diversas culturas. La promesa de Dios en Cristo llega a ser, ahora, una oferta universal, no ya limirada a un pueblo concreto, con su lengua y costumbres, sino extendida a todos

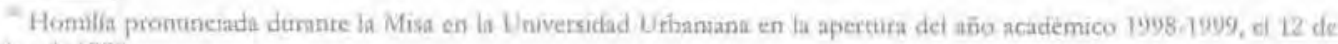
octubre de 1998 .
} 


\section{Or. Fidel González Fernăndez mcç}

como un patrimonio del que cada uno puede libremente participar. Desde lugares y tradiciones diferentes rodos están llamados en Cristo a participar en la unidad de la familia de los hijos de Dios. Cristo permite a los dos pueblos llegar a ser "uno" "I as culturas se alimentan de la comunicación de valores, y su vitalidad y subsistencia proceden de su capacidad de permanecer abiertas a la acogida de lo nuevo [...].Cada hombre está inmerso en una cultura, de ella depende y sobre ella influye. Êl es al mismo tiempo hijo y padre de la cultura a la que pertenece. [...]En consecuencia, toda cultura lleva impresa y deja entrever la tensión hacia una plenitud. Se puede decir, pues, que la cultura tiene en sí misma la posibilidad de acoget la tevelación divina. [...]El anuncio del Evangelio en las diversas culturas, aunque exige de cada destinatario la adhesión de la fe, no les impide conservar una identidad cultural propia., ${ }^{, 2 H}$

E1 Hecho guadalupano y el Beato Juan Diego Cuauhtlatoatzin entonces expresará y reafirmará hoy todo esto. He aquí también la singularidad e importancia de esta canonización, importante según nosotros, que nos señala el significado del Hecho del Verbo que encarnándose se ha unido al hombre para salvarlo. Aqui encontramos el camino que la lglesia está llamada a seguir para la evangelización.

Es innegable el profundo sentido mariano de la espiritualidad española que llega a México a través de conquistadores y misioneros españoles. También es innegable la devoción de muchos de ellos a la Virgen de Guadalupe de Extremadura, en España. Muchos de los conquistadores y misioneros de la primera hora procedian de aquella región española. Tal devoción los acompaña. La Virgen "pertenece" a la historia épica de la reconquista española; con frecuencia en la conquista militar del Nuevo Mundo y en la "conquista espiritual" del mismo, para usar las palabras del conocido libro de Robert Ricard $^{20}$, esta mentalidad los acompañará siempre y se mostrará en devociones $c$ iconografias. En este sentido cabe cl juicio de Richard Nebel de que la Virgen: "era garante de sus victorias, tal como lo había sido en España" "vi

Pero lo que es ya más dudoso es la tesis que el mismo autor afirma cuando se pregunta: "¿por qué entonces la Virgen deviene también en una figura central del cosmos religioso de los conquistados? Podemos decir que su función para los indios es "compensatoria". De un lado, la Virgen, y particularmente la de Guadalupe en el cerro Tepeyac, reemplaza a las deidades matemas o telúricas (Coatlicue, Cihuacoátl, Teteoinnan y otras) del antiguo sistema religioso tolreca-azteca, permitiendo de tal manera un cierto grado de continuismo espiritual. En términos socioculturales, la

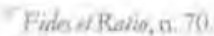

Ibidem, n. तI.

"Robert, RUCARD, Le conquista esperitual de Alevere, rad, españala FCH Mésicu 1986

"Richar Kari, NEBELL, Dhidem, 237
} 
veneración de la Virgen de Guadalupe permite a los indígenas, gracias a las circunstancias particulares de su aparición a un pobre indio la reivindicación de sus reclamos de respeto y de reconocimiento dentro de la sociedad colonial y de su participación de la espetanza de la salvación" "'. Se explica también razonablemente el uso del término Guadalupe para indicar a la Virgen Santa María, madre del Señor, que veneraban los cristianos llegados de España, que anunciaban los misioneros y que acogian explícitamente como tal neobautizados: indicación de una persona de una persona histórica real Maria de Nazaret bajo uno de las muchas advocaciones devotas de la tradición cristiana local, y no simplemente la transposición de un símbolo que podia tener ya descle sus comienzos un significado ambiguo ${ }^{32}$.

Estas afirmaciones son verdades a medias. Contienen datos incuestionables. Afirman la capacidad inculturadora del anuncio cristiano llevada a cabo por los misioneros, pero adolecen de una parcialidad, es decir: Guadalupe no es una simple sustitución; fue un acontecimiento histórico, percibido como tal por los más antiguos documentos a nuestra disposición. Solamente la afirmación clara de la historicidad puede llenar de contenido un símbolo que hace razonable una práctica y una dévoción mariana de la envergadura de Guadalupe en el caso.

Ciertamente la devoción a la Guadalupana, basada en el acontecimiento guadalupano constituye un punto notable de convergencia religiosa y cultural para los católicos mexicanos y creemos también para los latinoaniericanos, con una fuetza cada dia más grande. Hubo en el pasado manipulaciones como las hay hoy como las habrá en el futuro, sin embargo, el acontecimiento guadalupano sigue afirmando el método usado por Dios en la historia salvífica: el uso de un particular histórico que contiené en sí una dimensión universal. El acontecimiento guadalupano o es un hecho de la historia o símbolo fabricado con un objetivo ideológico. La documentación que aquí presentamos se propone ofrecer los datos de una investigación histótica que nos lleva razonablemente hacia la primera afirmación.

Dr. P. Fidel González Fernández mecj Universidades Pontificias Urbaniana y Gregoriana de Roma

\footnotetext{
"Richar Kard, NEBEL, Itidens, 237.

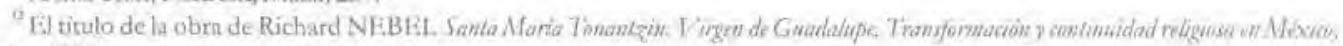
México 1995 , mantiene esta posición ambigua,
} 